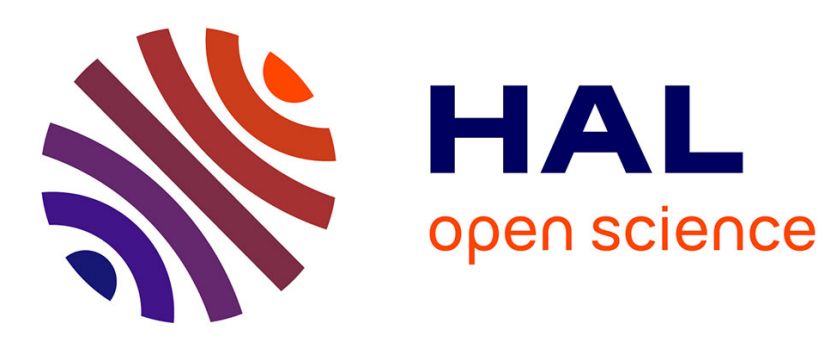

\title{
Ontology-Based Platform for Sharing Knowledge on Industry 4.0
}

\author{
Giulia Bruno, Dario Antonelli
}

\section{To cite this version:}

Giulia Bruno, Dario Antonelli. Ontology-Based Platform for Sharing Knowledge on Industry 4.0. 15th IFIP International Conference on Product Lifecycle Management (PLM), Jul 2018, Turin, Italy. pp.377-385, 10.1007/978-3-030-01614-2_35. hal-02075589

\section{HAL Id: hal-02075589 \\ https://hal.inria.fr/hal-02075589}

Submitted on 21 Mar 2019

HAL is a multi-disciplinary open access archive for the deposit and dissemination of scientific research documents, whether they are published or not. The documents may come from teaching and research institutions in France or abroad, or from public or private research centers.
L'archive ouverte pluridisciplinaire HAL, est destinée au dépôt et à la diffusion de documents scientifiques de niveau recherche, publiés ou non, émanant des établissements d'enseignement et de recherche français ou étrangers, des laboratoires publics ou privés. 


\title{
Ontology-based platform for sharing knowledge on Industry 4.0
}

\author{
Giulia Bruno and Dario Antonelli \\ Politecnico di Torino, Corso Duca degli Abruzzi 24, 10129 Torino, Italy \\ \{giulia.bruno, dario.antonelli\} @polito.it
}

\begin{abstract}
Industry is currently undergoing a digital transformation for strengthening its competitiveness through the convergence between industrial automation and data exchange technologies. This trend exploits a multiplicity of technologies from Cyber Physical Systems and intelligent robotics to PLM and big data management, in order to transform the manufacturing systems in a network of smart and autonomous agents. Even if most of the technologies are already available nowadays, the key obstacle lies in the lack of experience in operating with such technologies. To develop the required skills, different strategies for learning should be adopted. The paper describes the first outcomes of TIPHYS (http://www.tiphys.eu/), an EU funded project for the development of 'social network based doctoral education on Industry 4.0'. The project organizes the learning material as small didactic elements that are accessed through an ontology-based platform. PLM concepts are applied to allow learners to customize their learning path, to provide them with a dynamic repository, whose content evolves and is enriched by the collaborative contribution of students themselves. The ontology structure is described with the help of selected examples.
\end{abstract}

Keywords: Industry 4.0, PLM, Ontology, Collaborative learning.

\section{Introduction}

The term Industry 4.0 refers to the so-called "fourth Industrial Revolution". The purpose of Industry 4.0 is to create a smart factory characterized by a strong digitalization of processes and based on Cyber Physical Systems (CPS). The basic concept is to exploit mature ICT technologies by implementing them in the manufacturing sector in order to develop an interconnected production system.

Industry 4.0 is characterized by the integration along three dimensions: vertical integration together with networked manufacturing systems, horizontal integration through value networks, and end-to-end digital integration of engineering across the value chain of a product's life-cycle. CPS platforms are where the specific requirements for horizontal and vertical integration of CPS, applications, and services arise in business processes [1].

The technologies specific to this fourth industrial revolution defined as "enabling" are nine [2]: horizontal and vertical system integration, industrial IoT, cybersecurity, 
cloud, big data analytics, simulation, augmented reality, autonomous and collaborative robots, additive manufacturing.

It is apparent that there is a common set of concepts that pervades the different and apparently unrelated technologies. The need of explicating the underlying concepts that justify the clustering of all the technologies is pointed out by [3].

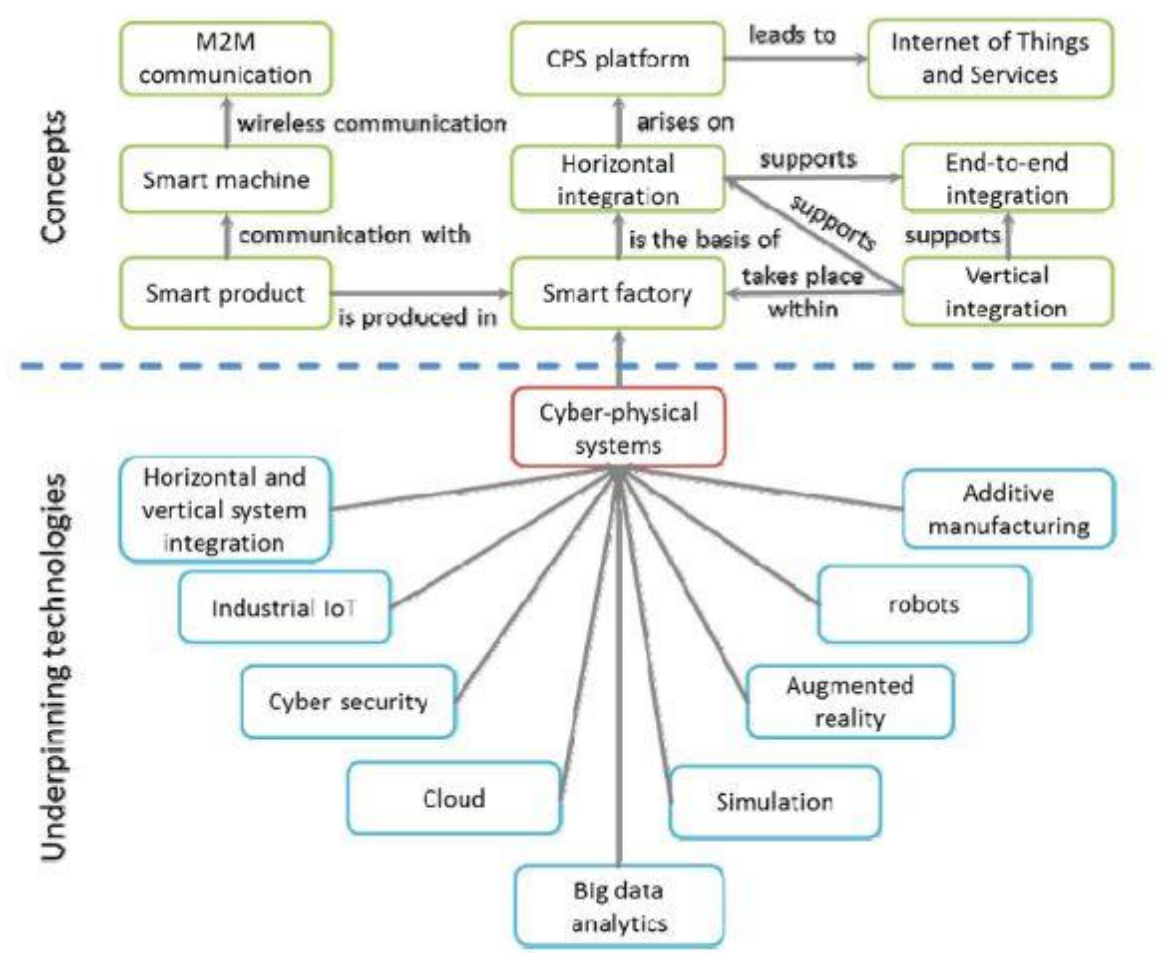

Fig. 1. The relationship among Industry 4.0 enabling technologies and the related core concepts (from [3]).

A study carried out among a large group of companies both adopting and nonadopting I4.0 technologies revealed a spread lack of knowledge on the subject [4]. It emerged that the non-adopters were not familiar with the issues of the fourth industrial Revolution that appeared as an evolution too far in the future.

An alarming feature common to adopters and non-adopters companies lay in their mentality that attributed scarce importance to the formation of the management on the issues of digital and smart factory.

The justification of present work is exactly the set up of a learning platform for the dissemination and the collaborative learning of Industry 4.0 concepts. The idea has given life to the EU project TIPHYS [5], whose preliminary results are presented here. 
TIPHYS aims at developing a platform that allows students to customize their learning path through a modular approach. It relies on building blocks defined through a design approach based on Constructive Alignment.

The adopted approach relies on defining and populating two ontologies: one of the learning process and the other on the concepts that constitute the core principles of I4.0. Defined the concepts and the relationships among them, it is possible to design a learning path that lead to the desired outcome in terms of knowledge of a specific enabling technology.

In the paper the TIPHYS project outcomes and its methods are shortly described in section 2. In Section 3 the problem of learning I4.0 is described with the help of a storyboard. In Section 4, the ontologies are described and in Section 5 they are implemented for a chosen case study. Finally, Section 6 draws conclusions and states future works.

\section{The TIPHYS project}

The objectives of the TIPHYS project is to build an Open Networked Platform for the learning of Industry 4.0 themes dedicated to university students and to industrial technicians by adopting modern learning strategies. Such strategies are Social NetworkBased Education (SNE) and Constructive Alignment (CA). In the view of educational paradigms, the concept of SNE could be a model that integrates features of the education 3.0 paradigm [6]. In SNE, students and teachers are participants that form a network, in which the network structure, communication, learning process and behavior exhibit features of a social network.

Constructive Alignment (hence CA) has emerged from the work of John Biggs as outstanding principle for devising effective and efficient pedagogical activities in higher education. CA builds upon two main concepts: the constructivist understanding of the learning process and the practical need for aligned and outcome-based curricula designing [7].

Therefore, SNE is focused on teamworking, building of interaction networks among students and teachers of different Universities and Countries. CA gives the necessary common framework for sharing educational objectives among different institutions and different teaching methodologies.

The ICT technologies supporting the project are the MOOC (Massive Open Online Courses) platforms and the virtual reality. MOOC allow offering a networked multinational learning content without the need of physical movement of students and teachers among the Universities. Virtual reality allows enriched interaction between the students when laboratory activities are needed for gaining specific skills. This is particularly important as the object of the present action is education in the field of Factory Automation.

The objectives of the project are to build an Open Networked Platform for the learning of Industry 4.0 themes. The project doesn't just create an open platform but a set of models to standardize the learning and physical processes as a "virtual copy" of the learning activities. The models are structured in a modular approach in order to 
promote the integration in the existing mechanisms as well as for future necessary adaptations.

The students will be able to co-create their learning track and the learning contents and dynamic student teams will be created for every specific learning requirement. Teams will interact using a Social Network application, without the necessity for physical presence.

\section{Motivation}

Learning to exploit I4.0 enabling technologies is a challenging task as they have a consistent number of connections with several disciplines and it is not known what exactly are the knowledge needed to implement the technology, to maintain the technology or simply to use it in a factory.

In the storyboard a fictitious manufacturing technician, with an electronic background, needs to setup a Cyber Physical System where a number of sensors mounted on a $\mathrm{CNC}$ are connected together and feed a simulator of the machine state for predictive maintenance purposes. As happens in I4.0, when ICT techniques are applied to factory machines, two completely different knowledge sets are involved. In this case the technician knows how to connect sensors to the factory network and how to extract relevant information to redirect to the LAN where the simulator receives inputs. On the contrary she doesn't know how to program CNC to slow down or stop the machine when a possible failure mode is detected or predicted.

Fig. 2 shows the storyboard of this situation. Without a learning platform, the learner has to find the materials on her own, and they cannot be in the right order. For example, she firstly finds a lesson on CNC with programming examples, but they are hard to understand without a previous knowledge of cutting processes and related parameters. Thus, she understands she has to find a lesson more general of cutting processes, and then finally come back to the details of the programming language (Gcode).

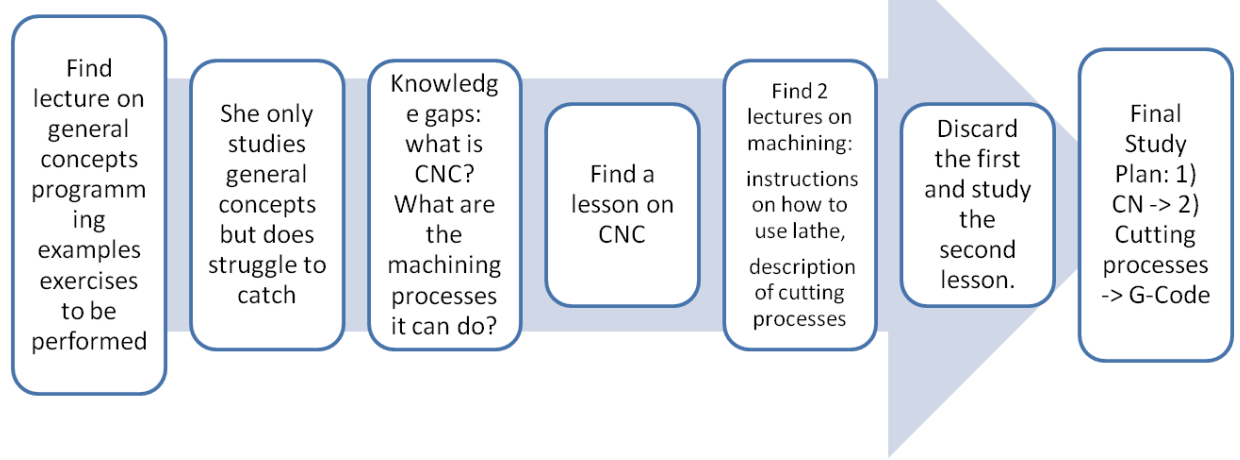

Fig. 2. Storyboard of a wrong learning path, due to the incorrect order of lessons found. 
By exploiting the TIPHYS learning platform, the precedence constrains among lessons are known, thus the learning path will be firstly studying the cutting processes, then the CNC and finally the G-code, as reported in Fig.3.

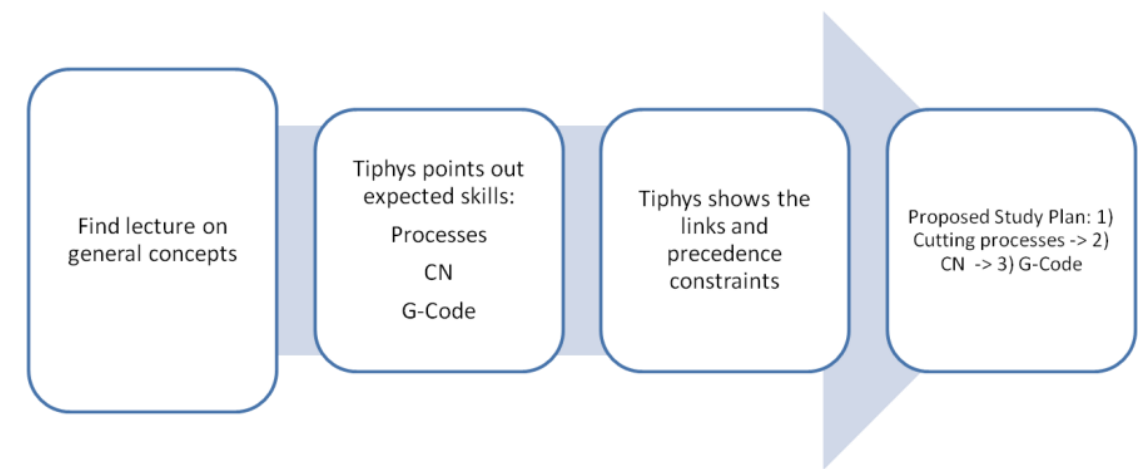

Fig. 3. Storyboard of a correct learning path, due to the exploitation of the TIPHYS learning platform.

\section{$4 \quad$ Ontology for learning Industry 4.0}

Ontologies plays a fundamental role in knowledge management because they formally specify the key concepts, properties, relationships, and axioms of a given domain [8]. They are used to structure and represent knowledge in a variety of industrial domains $[9,10]$. According to Imran and Young [11] the process of defining an ontology starts from the identification of the set of relevant concepts, then proceeds with the organization of concepts in a formal model representing the ontology structure, and finally performs the implementation of the model in ontology web language (OWL). This procedure was followed to define the two ontologies necessary for our purpose: one for Industry 4.0 and another for the learning process. They are described in the following subsections. Both of them are created by using the Protégé ontology editor (http://protege.stanford.edu).

\subsection{Industry 4.0 ontology}

The Industry 4.0 ontology contains all the concepts related to Industry 4.0, and the relationships among them. We take as reference the concepts and technologies represented in Fig. 1 and created the corresponding ontology in OWL.

Smart factory is a core concept component of Industry 4.0 [3]. It is the place where vertical integration together with networked manufacturing systems takes place. In a smart factory, products and machines communicate with each other, cooperatively driving production. Horizontal integration refers to the integration of multiple smart factories through value networks. Smart product is another critical concept component. Smart products can refer to objects, devices, and machines that are equipped with sensors, controlled by software and connected to the Internet. 
Industry 4.0 will give rise to novel CPS platforms geared toward supporting collaborative industrial business processes and the associated business networks. Technologies of nine aspects related to CPS involved in the process of turning the current industrial production to Industry 4.0 have been identified [3]. The application of CPS bring both cybersecurity issues and the generation of industrial big data, which requires cloud technology and data analytics for storage and analysis. The virtual world of CPS consists of a great variety of models of the production facilities, for which simulation can play an important role. Augment reality technology is required for operators to interact with CPS, while additive manufacturing and robots are essential parts of the CPS-based manufacturing systems of Industry 4.0. All these concepts are organized in the Industry 4.0, as shown Fig. 4.

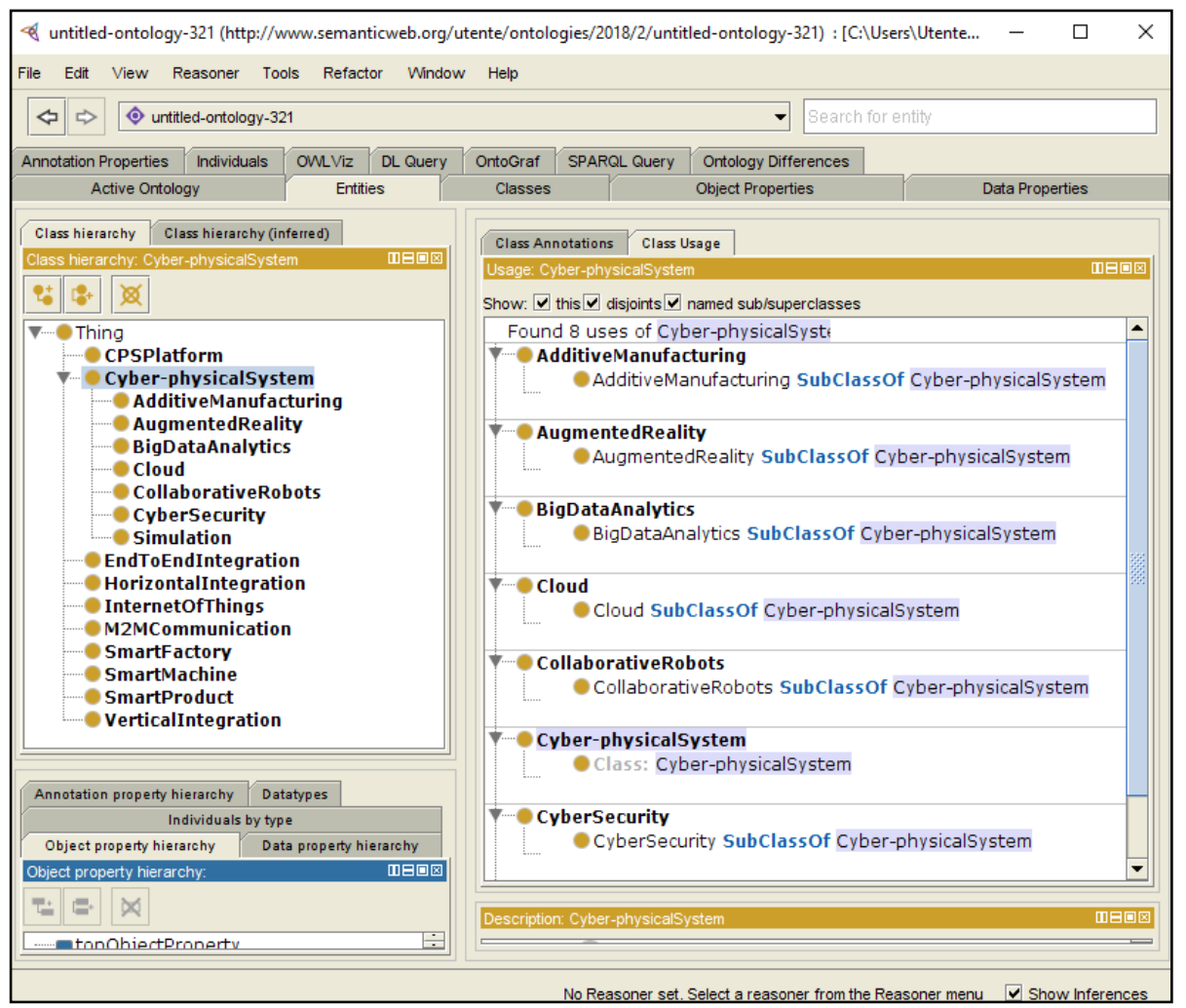

Fig. 4. Implementation in Protégé of the Industry 4.0 ontology.

\subsection{Learning ontology}

The learning ontology, accordingly to the constructive alignment philosophy (i.e., the CONALI ontology) was previously defined in [7]. The main concepts of this ontology 
are the intended learning outcomes (ILO), the teaching activities (TA), the assessment tasks (AT), and the educational goal verbs (EGV). An ILO is connected with the corresponding TAs, ATs and ECGs. Also TAs and ATs are connected to the involved EGV. We adopted this ontology by adding a relationship to represent the constraints between ILOs, i.e., which ILOs are preparatory to reach another ILO. The implementation of the learning ontology is shown in Fig.5.

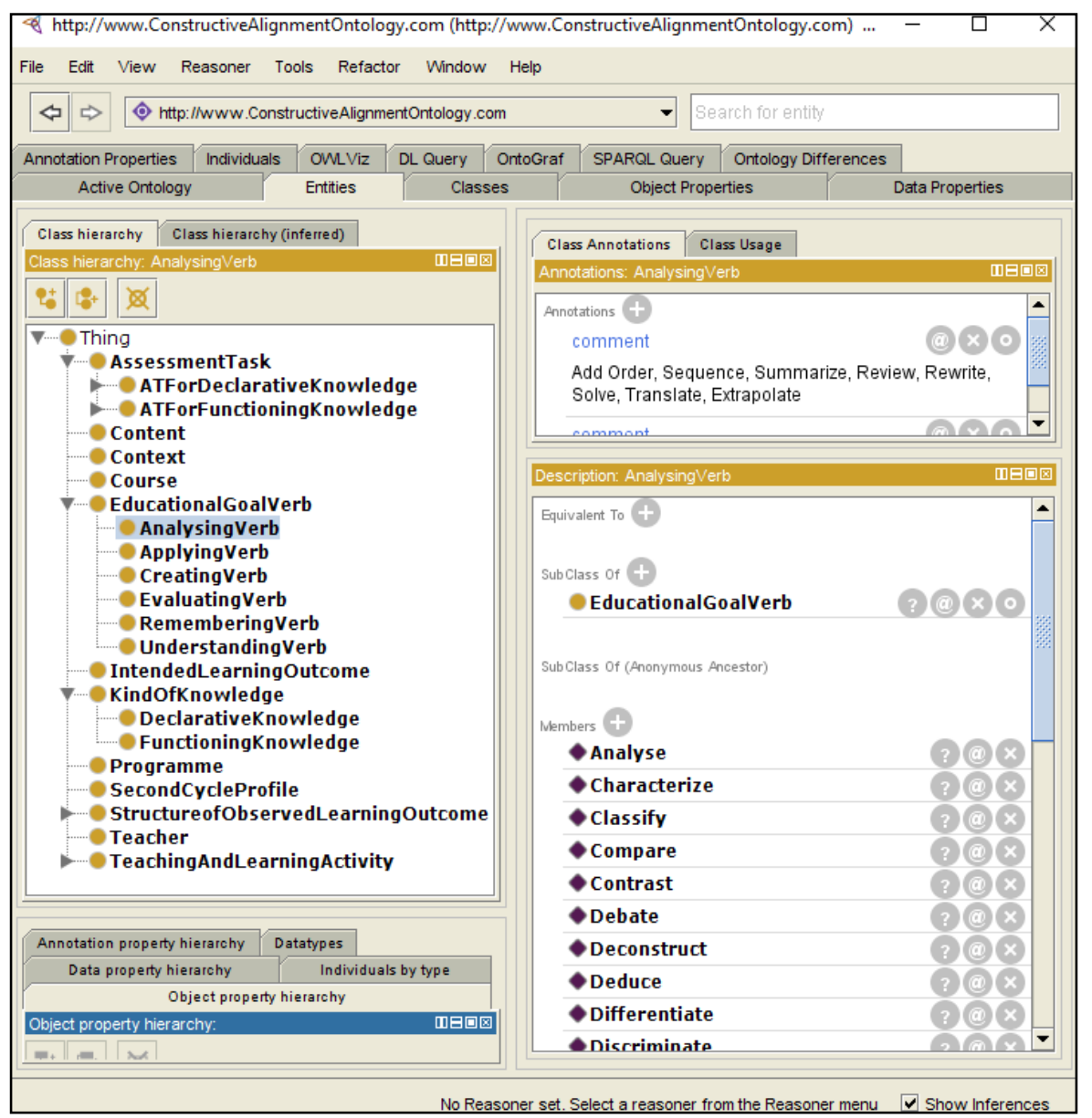

Fig. 5. Implementation in Protégé of the learning ontology.

\section{$5 \quad$ Ontology population and usage}

Both the ontolgies have to be populated in order to be used. The Industry 4.0 ontology is populated with the conceptes that specify the ones described in Section 4.1. For each concept, one or more learning outcome with the corresponding teaching activi- 
ties and assessment tasks is added in the Learning ontology described in Section 4.2. Furthermore, the precedence contraints among ILOs are lso inserted.

By making refernce to the example described in Section 3, Table 1 represents the ILOs available in the Learning ontology. In this case the precedence is limited to the ILOs associated to the same topic, but it is possible to have precedences also between different topics of Industry 4.0.

Table 1. Example of ILOs stored in the Learning ontology.

\begin{tabular}{lllll}
\hline \# ILO & $\begin{array}{l}\text { Kind of } \\
\text { knowledge }\end{array}$ & $\begin{array}{l}\text { Level of under- } \\
\text { standing (Verb) }\end{array}$ & Content & Precedent \\
\hline 1 & Declarative & Assess & Cutting processes & - \\
2 & Declarative & Select & Computer Numerical Control & 1 \\
3 & Functional & Program & G-code & 2 \\
\hline
\end{tabular}

\section{Conclusion}

This work aims at describing the set up of a learning platform for the dissemination and the collaborative learning of Industry 4.0 concepts, the main objective of the EU funded TIPHYS project. The adopted approach relies on defining and populating two ontologies: one of the learning process and the other on the concepts that constitute the core principles of I4.0. Defined the concepts and the relationships among them, it is possible to design a learning path that lead to the desired outcome in terms of knowledge of a specific enabling technology. Future works will focus on the development of a networked platform, based on the two ontologies developed, where students will be able to communicate and co-create their learning track and the learning contents.

\section{References}

1. Industrie 4.0 Working Group, 2013, " Securing the Future of German Manufacturing Industry-Recommendations for Implementing the Strategic Initiative," acatech, Munich, Germany, accessed Aug. 28, 2016.

2. Rüßmann, M. , Lorenz, M. , Gerbert, P. , Waldner, M. , Justus, J. , Engel, P. , and Harnisch, M. , 2015, "Industry 4.0: The Future of Productivity and Growth in Manufacturing Industries," The Boston Consulting Group, Boston, MA, accessed Aug. 28, 2016.

3. Yongkui Liu, Xun Xu, Industry 4.0 and Cloud Manufacturing: A Comparative Analysis, University of Auckland, New Zealand, 2017.

4. Federmeccanica, I risultati dell'indagine Industria 4.0 condotta da Federmeccanica, 2016.

5. Tiphys, Social Network based doctoral Education on Industry 4.0. Erasmus Plus KA2 Strategic Partnership, Project No: 2017-1-SE01-KA203-034524 
6. Putnik, G.D., \& Putnik, Z. (2010). A semiotic framework for manufacturing systems integration-Part I: Generative integration model. International Journal of Computer Integrated Manufacturing, 23(8-9), 691-709.

7. Maffei A., Daghini L., Archenti A., Lohseb N., CONALI Ontology. A Framework for Design and Evaluation of Constructively Aligned Courses in Higher Education: Putting in Focus the Educational Goal Verbs, 26th CIRP Design Conference, 2006.

8. Bruno, G., Antonelli, D., Korf, R., Zimmermann, N. Exploitation of a Semantic Platform to Store and Reuse PLM Knowledge. In:IFIP Advances in Information and Communication Technology, 438, pp. 59-66 (2014).

9. Bruno, G., Antonelli, D., Villa, A. A reference ontology to support product lifecycle management, Procedia CIRP (2015)

10. Bruno, G., Villa, A. An ontology-based model for SME network contracts, Lecture Notes in Computer Science (2012)

11. Imran, M., and Young, B. The application of common logic based formal ontologies to assembly knowledge sharing. Journal of Intelligent Manufacturing, 26(1), 139-158 (2013). 